\title{
Tendencias actuales de la teología moral en América Latina
}

\author{
Dean BrackJey, \\ Centro de Reflexión Teológica, \\ San Salvador.
}

En la teología latinoamericana, sobre todo la católica, desde el Vaticano II, pueden distinguirse tres grandes corrientes: la teología tradicionalista, que apela con frecuencia al magisterio eclesiástico, la teología progresista post-conciliar y la leología de la liberación. Este pluralismo refleja diferentes proyeclos pastorales, eclesiologias y alianzas sociales. En algunas ocasiones, las tres corrientes se mezclan, y a cada una de ellas le es propia una teología moral'.

En este ensayo, examinaré la teología moral de América Latina, especialmente en lo que se diferencia de la de otros lugares, tal cómo ha ido evolucionando, en estos últimos años. No es posible tratar todos los temas, y por ello, me concentraré en dos: algunos aspectos de moral fundamental y el problema moral más grave de América Latina: la pobreza masiva y la desigualdad estructural.

\section{Teología moral de la liberación y la solidaridad}

Lo que distingue a la teología moral en América Latina es, sobre todo, el método y la problemática específica de la teología de la liberación, entendida ésta en sentido amplio. $Y$ es que, aunque no es simplemente teología moral, la teología de la liberación surgió de la indignación élica e inspiró una nueva manera de hacer teología moral'2. Sin embargo, hasla hace poco, esta teología

1. Cfr. Josć Anlonio Lobo, "Lineas y iendencias de la Icología moral latinoamericana", Moralia 17 (1995), 343-360.

2. H. M. Yáñcz, “Élica de la libcración. Aproximación metodológica, estado de la cuestión y perspectivas del luturo", Stromasa 49 (1993), 109-183; csp. en la p.123. Scgún Jon Sobrino, la tcología de la liberación es formalmente intellectus amoris, J. Sobrino, "Teología en un mundo sufricnle. La tcología de la libcración como intellectus amoris", Revisia Latinoamericana de Teologia 15 (1988), 243-266. 
moral, que puede llamarse "de la liberación", sugerente y prometedora, ha sido fragmentaria y poco sistemática", aunque los textos de Antônio Moser y Bernardino Leers, co-autores, y de Tony Mifsud ya marcaron avances importantes.

Dos escritos recientes de Mauricio García Durán y Carlos Novoa, ambos colombianos, ofrecen un buen resumen de las líneas maestras de la teología moral, que se desarrolló durante los setenta y los ochenta. La teología y la realidad histórica han cambiado mucho, en los últimos años, pero se sigue utililizando mucho aquel discursc, aunque pocos insistan ya en la etiqueta "teología de la liberación".

Como es sabido, el mérodo de la teología de la liberación "clásica"s es más importante que sus conlenidos específicos. Según eso, y en primer lugar, la teología moral es "acto segundo", que presupone el acto primero de compromiso próxico. Así, la ortopraxis debe alimentar la reflexión moral, y viceversa. En segundo lugar, la teología moral asume la perspectiva de los pobres (como lo ha enfatizado G. Gutiérrez para la teología en general). Por último, la teología moral utiliza tres "mediaciones", o instrumentos teóricos, para iluminar la realidad: el análisis empírico, en especial de las ciencias sociales (a lo que algunos añaden la filosofía y la imaginación utópica"), la interpretación teológica y las orientaciones prácticas ${ }^{7}$. Estas mediaciones corresponden al conocido método de la acción católica: ver, juzgar y actuar.

Recientemente, Carlos Novoa ha resumido el contenido teológico de la teología moral, desde una perspectiva liberadora ${ }^{*}$. La teología moral en América

3. Cfr. Julio Lois y José Luis Barbero, "Élica cristiana de liberación en América Latina", Moralia 10 (1988), 91-118; Marciano Vidal, Moral de actitudes, Vol. III, 8a cd., Madrid, 1995, p. 186; F. Moreno Rejón, "Moral fundamental en la tcologia de la liberación”, Mysterium liberationis: conceptos fundamentales de la teologia de la liberación, 1. Ellacuría y J. Sobrino (eds.), San Salvador, 199I, Tomo I, p. 274.

4. A. Moser y B. Leers, Teología moral. Confliclos y aliernativas, Madrid, 1987; T. Milsud, Moral de discernimiento, 4 vols., Santiago, 1984, con ediciones revisadas hasla 1994.

5. Para lo que siguc, véasc Mauricio García Durán, "Tcología moral y opción por los pobres: anotaciones desde la perspectiva del método". Theologica Xaveriana 47 (1997) 65-84.

6. Moreno Rejón, "Moral fundamental", pp. 280, 284-285; cfr. Ignacio Ellacuría, "Utopia y profelismo", Mysterium liberationis, Tomo l, pp. 393-442.

7. Cfr. Clodovis Boff, "Epistemología y mélodo de la teología de la liberación", en Mysterium liberationis, Tomo I, pp. 79-113. El brasilcño Márcio Fabri dos Anjos pone primero el momento hermeneútico para establecer criterios y referencias básicas; en segundo lugar, viene el análisis de la realidad, a la luz de estos crilerios. Cfr. M. F. dos Anjos, "Bioćtica nas desigualdades sociais", en $A$ bioéfica no século $X X I$, Volnei Garrafa y Sergio F. lbiapina Costa (eds.) Brasilia, 2000, pp. 49-65.

8. Carlos Novoa M., El seguimiento histórico de Jesús según el Espíritu. Formación de la conciencia moral, Santafé de Bogotá, 1995. Novoa compara la lcología de la 
Latina, afirma que la vida moral consiste en la práclica del amor, en el seguimiento. Seguir a Cristo no es simple imitación, sino que, como lo ha enfatizado Jon Sobrino, implica encarnarse en el mundo actual y responder a su realidad con creatividad, como respondió Jesús, a la realidad de su mundo".

Además, la moralidad cristiana surge de un encucntro con Dios, en comunidad. Hunde sus raíces en una espiritualidad de infancia espiritual (G. Gutiérrez). Busca discernir y realizar la voluntad de Dios, que consiste en la realización de su reino entre nosotros, en forma de una "liberación integral", novedad que abarca a personas, a una sociedad fraterna y a la Iglesia. Responder al don de Dios implica oplar por los pobres y llevar a cabo una praxis de transformación social ${ }^{\prime \prime \prime}$.

Este pudiera ser el resumen de la moral fundamental, desde la perspectiva liberadora, antes de los importantes cambios sociales que surgicron con ímpetu en los años ochenta: el colapso del bloque soviético y el fracaso de los movimientos revolucionarios, en América Latina, el surgimiento de la "nueva economía" y la consolidación del capitalismo neoliberal con sus programas de ajuste estructural, el desempleo estructural y la crisis de la deuda externa, la crisis de legitimación de la política tradicional (gobiernos, partidos y movimientos guerrilleros), el crecimiento del feminismo, de la nueva conciencia afroamericana y de los grupos indigenas, la nueva conciencia ecológica, la restauración conservadora en la Iglesia católica, el desafío del pensamiento posmodemo, y, finalmente, la creciente desintegración social — por un lado- y la proliferación de gnipos no gubernamentales de la sociedad civil —por olro. Todos estos fenómenos sociales han tenido su impacto en la teología latinoamericana, y, en particular, en la moral.

Antes de especificar y analizar las tendencias actuales, hay que tener en cuenta un dato de singular importancia. Aunque sea difícil generalizar elementos de la teología moral latinoamericana, nos parece evidente que la categoría de solidaridad se ha ido convirtiendo en eje principal, en torno al cual se organizan los demás temas. Esto se puede alirmar, en la práctica, de todos los teólogos morales de América Latina. Por tomar un caso, Miguel Yánez de Argentina

conciencia moral desarrollada por los europeos Josef Fuchs, Klaus Demmer y Marcelino Zalba con la teologia moral latinoamericana, especialmente la de la liberación.

9. Cfr. J. Sobrino, Jesús en América Lasina, San Salvador, 1982, pp. 156-162. Para un resumen reciente de la teologia del seguimiento de Sobrino, véase Javier Alonso Castro C., "El absoluto moral en la reflexión cristológica de Jon Sobrino", Theologica Xaveriana 47 (enero-abril 1997) 55-64.

10. Moreno Rejón añadiría: uno no pregunta simplemente cómo ser bueno en esta sociedad "perfeccionable", sino cómo. 
propone "un nuevo modelo desde la categoría solidaridad"", aunque sin abandonar la perspectiva de la liberación. La solidaridad y la esperanza son dos dimensiones claves de la existencia humana, afirma Yáñez. Somos seres-en-relación, que se humanizan amando. La solidaridad es amor social, reconocer y respetar al otro y a la otra. Ser humano es también esperar, proyectarse hacia el futuro. Una ética de la solidaridad esperante corresponde a lo que realmente somos'2.

La solidaridad pasa a ser el centro de la moral porque, en primer lugar, da respuesta al individualismo y a la competilividad de un ethos liberal cada vez más generalizado, en el conlinente, y en segundo lugar, porque da respuesta a la exclusión socioeconómica. Eslo último es de suma importancia. En su primera fase, la leología de la liberación enfatizó la dependencia económica de América Latina de los países ricos, pero la globalización ha hecho cambiar los matices del hecho de la dependencia. En lo que todos están prácticamente de acuerdo es en echar mano de la exclusión como la categoría principal para describir la actual problemálica social. Es un hecho evidente que, en las dos últimas décadas, la "nueva economia" y los programas neoliberales de ajuste estructural han generado exclusión económica y social (como se verá más adelante). En tercer lugar, para muchos, la solidaridad parece traducir el agape neotestamentario en lérminos de las culturas latinoamericanas. Por último, ya que los documentos eclesiásticos recientes enfatizan la solidaridad"3, incluso las corrientes calólicas muy conservadoras utilizan este lenguaje. La conclusión es que se puede caracterizar la teología moral de América Latina de diversas formas, pero en todas partes es hoy una teología de la solidaridad. Como la solidaridad se puede entender de diversas maneras, habrá que analizar si y cómo refuerza, complementa o llega a desplazar el tema de la liberación, en los diversos autores.

Junto al principio solidaridad, por así decirlo, la teología moral latinoamericana ha ido abordando de manera novedosa una serie de temas. Se ha reflexionado amplia y profundamente sobre la economía neoliberal, la doctrina social calólica, la mujer, el medio ambiente, la bioética, los derechos humanos y la deuda externa. La cultura y la etnicidad reciben más atención que antes, en particular las realidades afroamericanas e indígenas. Se nota un interés nuevo

11. H. Miguel Yáñez, Esperanza y solidaridad. Una fundamentación antropológicoteológica de la moral cristiana en la obra de Juan Alforo, Madrid, 1999, p. 30; cursiva en el original.

12. Ibid. Véase "Conclusiones," Capítulo 9, pp. 373-393, y el reciente artículo del mismo autor, que amplia estas reflexiones, H. M. Yánez, "Jalones para fundamentar una ética de la solidaridad esperante," Stromata 56 (2000), 1-26. Véase también el número 64 de la revista costaricense Senderos 22 (enero-abril 2000), dedicado al tema de la solidaridad.

13. Véase, por ejemplo, Cap. V, "Camino para la solidaridad", en Juan Pablo II, "Ecclesia in America", Ecclesia, 6 de febero de 1999, 179-202. 
por consolidar la renovación post-conciliar de la moral, con mayor énfasis en la libertad, y se ha avanzado en la fundamentación filosófica de la ética teológica.

Lamentablemente, las limitaciones de espacio no nos permiten tratar en detalle la tolalidad de temas. Elegimos una serie de ellos, relacionados con el problena de la pobreza masiva y la economía de mercado, dejando para olra oportunidad temas tan importantes como el medio ambiente, el sida, los derechos humanos, la ética feminista, la bioélica y la deuda ${ }^{14}$.

\section{Desigualdad, neoliberalismo y mercado}

El problema moral más grave de América Latina es la pobreza y la desigualdad estruclural. Tiene dimensiones económicas, políticas, sociales y culturales. La "nueva economía" de alta tecnología y la globalización no sólo están reconfigurando las economías locales, sino también las relaciones entre economía, Estado y sociedad civil. Una parte de la globalización consiste en la explosión de la comunicación digital, pero otra parte decisiva consiste en la aplicación de las polílicas macroeconómicas, llamadas "neoliberales".

Esto es hoy reconocido por muchos, pero para poner el problema en un contexto actual, quizás sea bueno detenerse brevemente en un documento publicado en 1996, por los superiores mayores de la Compañía de Jesús de América Latina y el Caribe. Se trata de una carta, a la cual se añade un documento de estudio, sobre el neoliberalismo, en el continente ${ }^{15}$. Ambos textos circularon ampliamente.

El documento de estudio define el neoliberalismo como "una concepción radical del capitalismo que tiende a absolutizar el mercado hasta convertirlo en el medio, el mélodo y el fin de lodo comportamiento humano inteligente y racional. [...] Esle mercado absoluto no acepta regulación en ningún campo"16. Esle modelo del capitalismo es identificado con frecuencia con los gobiernos de Reagan y Thatcher, y ha sido promovido de modo agresivo en América Latina,

14. Para algunos de estos temas, véase Dean Brackley y Thomas L. Schubeck, "Moral Theology in Latin America", Theological Studies 63 (March 2002) 123-160.

15. Fue publicado en muchos lugares. Citaremos de "El neoliberalismo en América Latina. Carta de los provinciales latinoamericanos de la Compañia de Jesús" y "Aportes para una reflexión común. Documento de Trabajo", Estudios Centroamericanos 583 (mayo 1997) 475-479 y 479-488, respectivamente. El filósolo argentino Carlos Hoevel hace un análisis claro de cómo la economía globalizante ha afectado a América Latina (Carlos Hoevel, "Globalization Seen from the South", Communio 27 [2000] 511-31). Critica las evaluaciones más importantes del neoliberalismo; sus propias recomendaciones, sin embargo, son un tanto críplicas.

16. Provinciales, “Aportes”, No. 2, p. 479. 
desde 1980, en especial, por las instituciones financieras internacionales, como el Fondo Monetario Internacional y el Banco Mundial. Por su medio, los poderes industriales impusieron programas de ajuste estructural como condición para aliviar la deuda externa y para nuevos créditos, en general. El así llamado "consenso de Washington" de principios de política macroeconómica, que respaldaba el modelo, entró en crisis, a partir de las crisis financieras de México (19941995) y de Asia oriental (1997-1998) - y la actual super-crisis argentina, ciertamente, des-legitimará aún más este modelo y su marco teórico ${ }^{17}$.

El documento de los jesuilas articula posturas de amplia aceptación entre los cristianos. Todos los moralistas, ellos y ellas, que he estudiado, comparten su visión general. Según este "consenso latino", el mercado es un medio útil, y hasta necesario, para estimular la producción y organizar la distribución de recursos - y lambién, el documento de los jesuilas reconoce que incluso los programas de ajuste estructural han producido beneficios. Sin embargo, en el conlexio de la "nueva economía" (la economía de la alta tecnología con la robotización y la comunicación digital), el exesivo énfasis en el mercado libre ha agravado la desigualdad social, ha concentrado la riqueza y el ingreso aún más, y ha dejado a millones de seres humanos atrapados en la miseria. La principal división social, en la actualidad, ya no es entre el capital y el trabajo industrial, sino entre quienes están integrados en el mercado y los excluidos de él. Los gobiernos han abandonado funciones que son necesarias para proteger a los débiles y al medio ambiente, y para asegurar el bien común; miles de empresas locales han quebrado, cuando se han eliminado los controles sobre la inversión extranjera; la especulación financiera ha desestabilizado economías nacionales enteras. Las nuevas relaciones económicas han desgarrado la sociedad, generando el desempleo, la delincuencia y la corrupción, y desplazando a poblaciones rurales $\mathrm{e}$ indígenas.

La mayoría de teólogos también estaría de acuerdo en que las políticas neoliberales reflejan "una cultura fundada en una concepción de la persona y de la sociedad humana ajena al ideal cristiano"' no sólo el consumismo, sino también el individualismo y la competencia exagerada. El neoliberalismo socava, además, los valores espiriluales, comunitarios y familiares.

Ante estos hechos, los teólogos latinoamericanos no ofrecen fórmulas simples para una sociedad altemativa. Sin embargo, la mayoría estaría de acuerdo con respecto a la meta por la que se debe luchar, es decir, una sociedad "donde

17. Para una crílica penctrante del consenso de Washinglon y las políticas neoliberales, véase el nuevo libro del premio Nobel Joseph E. Stigliz, Globalization and its Discontents, New York, 2002.

18. Provinciales, “El neoliberalismo”, No. 2, p. 475. 
nadie quede excluido del trabajo y del acceso a bienes fundamentales para la realización personal como la educación, la nutrición, la salud, el hogar y la seguridad [...] Una sociedad atenta a las tradiciones culturales locales [...] Una sociedad democrática, construida participativamente"1".

Los diagnósticos y la meta son terreno común para los teólogos, pero, ante ello, se ubican en lugares distintos. Así, se puede distinguir entre moralistas que son más escépticos del mercado, que están más influenciados por tradiciones marxistas y la teoría social crítica, que son más sensibles a los obstáculos que presentan los intereses de clase, y moralistas que tienen menos temor a las fuerzas del mercado y que se apoyan más en la doctrina social católica. El primer grupo tiende a favorecer la iransformación de la sociedad, en orden a construir una alternativa al capitalismo. El segundo grupo favorece la reforma del capitalismo, que, a veces, es una reforma radical.

\subsection{Hacia la transformación social: evangelio y teoría crítica}

Uno de los teólogos que aboga por la transformación social es el brasileño, nacido en Corea, Jung Mo Sung. Forma parte de un grupo de teólogos que hace liempo critican el capitalismo, desde crilerios teológicos. Recientemente, Sung ha llamado la atención sobre el hecho de que los teólogos de la liberación más citados no tratan temas económicos en profundidad $d^{31}$, ausencia que contrasta, dice, con los primeros años de esta leología. Según Sung, la razón principal de esta anomalía es la problemática relación entre teología y ciencias sociales. Más en concreto, los teólogos no critican la economía, ni la teoría económica en términos teológicos. Para superar esta situación, afirma, es necesario reconocer, con Franz Hinkelammert, que la modemidad no se caracteriza tanto por la secularizacón como por el desplazamiento de lo sagrado. Tanto el proyecto capitalista burgués como el proyecto socialista marxista promete una salvación terrestre, y ambos terminan sacrificando a víctimas, en nombre de sus respectivos ídolos: el mercado para unos, el plan económico para otros. La moderna teoría social justifica estos proyectos "científicamente," pero, en realidad, están cargados de pretensiones religiosas".

19. Ibid., Nos. 17-20, p. 477.

20. Jung Mo Sung, Economía. Tema ausente en la teologia de la liberación, San Josć, Costa Rica, 1994.

21. Ibíd., p. 207. Sung clabora estos tcmas más en delalle en "Contribución de la tcologia en la lucha contra la exclusión social", Persona y sociedad (Santiago de Chilc) Vol. XI, No. 3 (dicicmbrc 1997) 23-39. Su aplicación del concepto de René Girard de "dcsco mimćtico" al consumismo y la competencia de la socicdad capitalista es especialmentc sugerente (cfr. ibid., pp. 27-29). 
Sung critica el "romanticismo anticapitalista"22 de aquellos cristianos, incluyendo a los teólogos, que expresan indignación moral por la miseria generalizada, 'pero luego llaman, con cierta ingenuidad, a la justicia distributiva. Lo que hace falta, dice, es analizar y evaluar en términos teológicos los mecanismos de producción, distribución y consumo, además de las teorías (de Weber, Popper, von Hayek, etc.), que justifican el capitalismo de mercado librc. Esta es, precisamente, la teología que produce Hinkelammert, en Costa Rica, Dussel, en México, y los brasileños Hugo Assmann, Julio de Santa Ana y Rubem Alves. Sung se queja de que los demás teológos de la liberación parecen ignorarlos o no tenerlos en cuenta.

Como otros teólogos latinomericanos, pero más sistemálicamente que la mayoría, Franz Hinkelammert retoma la crítica de la escuela de Frankfurt al uso exclusivo de la racionalidad instrumental (medio-fines), en las ciencias humanas modernas. En particular, critica cómo la ciencia económica sólo busca los medios adecuados para fines predeterminados, asumiendo que los fines que hay que propiciar no son objetos propios de la ciencia, sino sólo del guslo personal. Por principio, la leoría económica prescinde de la mela de la reproducción de la vida. En la práctica, dice Hinkelammert, la leoría neoclásica de precios termina midiendo sólo "los deseos o preferencias del consumidor", haciendo caso omiso de las necesidades vitales. Mientras tanto, los valores reinantes del mercado sin freno - la eficiencia y la competencia - conducen a la destrucción humana y ambiental. Según Hinkelammerl, estamos corlando la rama en la que estamos sentados. Este es un juicio (¡científico!) de hecho, no un juicio de valor, pero es un juicio que la ciencia económica excluye por principio. Acusa a Weber y a Paul Samuelson de irresponsabilidad por excluir de la ciencia económica el tema empírico de las consecuencias, de vida y muerte, del funcionamiento eficiente de los mercados ${ }^{23}$. Para Hinkelammerl, es imperativo optar por la vida y en contra de la aniquilación. La vida es el valor central de la ética. "La opción de no cometer suicidio fundamenta [...] toda ética posible"24 e invalida todo proyecto social que conduzca a la eliminación de los participantes ${ }^{25}$.

Hinkelammert concluye que la racionalidad instrumental de la teoría del precio debe ser subordinada a la racionaldad más amplia de la reproducción de la vida. Lo que Marx llamó "valor de cambio" (el valor en el mercado, medido por el precio) debe subordinarse al "valor de uso" (la utilidad para producir vida).

22. Sung, Economia, p. 100.

23. Franz J. Hinkclammert, El mapa del emperador. Determinismo, caos, sujeto, San Josć, Cosıa Rica, 1996, Capílulo 1; palabras ciladas de la p. 26; cfr. ibíd., pp. 90-91, 118-119, 214-217.

24. Franz J. Hinkelammcrl, Cultura de la esperanza y sociedad sin exclusión, San José, Costa Rica, 1995, p. 322.

25. Hinkclammerl, El mopo, p. 167. 
De lo contrario, la racionalidad instrumental produce irracionalidad. El reto actual es cómo combinar la teoría del precio neoclásica (que Marx desconoció, pero que sí es útil) con la racionalidad de la reproducción de la vida, subordinando así el mercado a las necesidades vitales. Ciertamente, la mayoría de los teólogos latinoamericanos estará de acuerdo con esta conclusión. Pero para Hinkelammert, a diferencia de otros, esto implica una transformación social en orden a crear "una sociedad de mercado, que no sea capitalista"

Hinkelammert no cree en las ilusiones trascendentales de la modernidad. No cree en utopías, en el sentido más estriclo de soluciones definitivas, en la historia. Descarta todo determinismo histórico de derecha y de izquierda. Pero sí coincide con los zapatistas de Chiapas en que la meta de la praxis debe ser "una sociedad en la que quepan todos", en la que nadie quede excluido. Como la misma prohibición de suicidio, este criterio de la no-exclusión es una norma negativa, que no depende de una teoría particular de la vida o de una estrategia particular de realizarla. Implica "no debes buscar tu buena vida de un modo tal que le quile al otro sus posibilidades de vivir"27. Inspira una praxis de resistencia, pero no una estrategia específica, como la búsqueda del poder estatal. La tarea aclual es la de luchar continuamente, "por medio de la acción asociativa y solidaria"2x, para ordenar las relaciones de mercado y hacer real una liberlad suficiente para que todo ser humano pueda vivir y el medio ambiente pueda florecer.

En una sociedad dominada por el mercado, dice Hinkelammert, las acciones tienen "efectos no-intencionales [...] que relornan sobre el propio actor y ejercen sobre él un efecto compulsivo"2u. Para Marx, la autonomía real, que la modemidad aprecia tanto, exige que se "disuelvan" estas fuerzas. Para Hinkelammert esto lo exige la misma sobrevivencia. La solución que propone es la acción solidaria. Sólo la acción solidaria y las instituciones de solidaridad (por ejemplo, la democracia) pueden "disolver" las fuerzas destructivas coercitivas, producidas por los mecanismos del mercado. Se trata de una tarea permanente.

El valor central de la ética y la meta de la acción es la vida misma. La acción solidaria es el medio indispensable para asegurar la vida humana y la integridad del medio ambienle. La solidaridad se basa en el reconocimiento del otro, como diría E. Lévinas, sobre todo de la víclima, reconociendo su dignidad y sus necesidades. La acción solidaria no constituye un valor "idealista", dice Hinkelammert; no es un valor en sí mismo. Es útil para promover la vida. Pero él insiste que la acción solidaria no se somete al tipo de cálculo de utilidad del

26. Ibid., Capítulo IIl; cita en p. 106.

27. Hinkelammert, Culiura de la esperanza, pp. $311,313$.

28. Hinkelammert, El mapa, p. 259.

29. Ibid., p. 243. Véase también Cultura de la esperanza, Parte III, Capitulo IV; El mapa, Capitulo III. 
actor individual, que convierte la solidaridad en egoísmo iluminado. La solidaridad es también acto de fe, en que mi propio bien participa en el bien de la comunidad humana y del medio ambiente. Hinkelammert acepta la traducción del mandamiento de amar al prójimo —que atribuye a E. Lévinas-: Ama a tu prójimo; tú mismo eres ese prójimo. Es decir, perderte en la solidaridad es encontrarte ${ }^{\text {w) }}$.

Todas estas reflexiones son, sin duda, muy profundas, incluso las últimas. Pero, en mi opinión, es innecesario y peligroso negar el valor intrínseco de la acción solidaria". Cede, creo, demasiado terreno a esa dicolomía que Weber abre entre una élica ("utilitaria") de responsabilidad y otra ("idealista") de convicción. Para integrar mejor los principios morales de la solidaridad y la obligación de promover la vida, ayuda caracterizar la solidaridad, entre otras cosas, como virtud moral (con valor de por sí), que busca promover la vida, que es valor ontológico y a la vez moral.

El brasileño Hugo Assmann coincide con Hinkelammert en que el imperativo fundamental es promover la vida y que, para hacerlo, hay que asumir la tarea difícil de combinar la solidaridad con una "economía-con-mercado":.12. Assmann prefiere esta última expresión a la de "economía de mercado", argumentando la necesidad de medidas, constituidas democráticamente, que circunscriban las operaciones del mercado para asegurar la satisfacción de las necesidades básicas de todas las personas.

Para Assmann, esto exige repensar el significado del "sujeto élico", tanto personal como social, porque ahora apreciamos mejor que nuestras acciones están inscritas en sistemas auto-regulados, que producen vastos efectos nointencionales. Para Assmann, esto implica que "la teoría moral y jurídica tradicional sobre los actos humanos [...] es tolalmente insuficiente"”." La ética ya no puede centrarse sólo en la conciencia, ni siquiera en la concientización social, ya que "la libertad y la conciencia están insertas [...] en procesos de la compleja auto-organización de la vida, y en procesos de acentuada auto-regulación de las esferas semi-aulónomas, que constiluyen los sistemas dinámicos bio-socio-económicos".:4.

30. Cfr. cl aparlado "Solidaridad, ncccsidad y ulilidad", cn Hlinkclammerl, El mapa, pp. 260-266; idem., Cultura de la esperanza, p. 357.

31. En otro cnsayo, Hinkclammert parece contradecir csta tcsis, cfr. El mapa, pp. 54 55.

32. Hugo Assmann, “Temas-chave para um referencial ćlico-polílico: Corporcidade —sujcito- mercado", Revista Eclesiástica Brasileira 57 (1997) 265-287; cita cn p. 268. Este arlículo presenla temas nucvos y otros ya claborados por el autor, en cscritos antcriores.

33. Ibid., p. 270.

34. Ibid., p. 280. 
Los enfoques habituales de la ética brindan poca posibilidad de cuestionar la idea de los liberales de que el mercado y la sociedad funcionan como organismos que se autoregulan. De acuerdo a esta teoría, las intervenciones ocasionales son suficientes para restaurar las condiciones del libre mercado que, por sí solo, tiende hacia un equilibrio perfecto. La acción directa para realizar la justicia social es, por tanto, innecesaria. Gracias a la "mano invisible" de Adam Smith, todos podemos buscar nuestro propio interés con la conciencia tranquila. De este modo, dice Assmann, el "mito" liberal del equilibrio perfecto y la mano invisible llevan a la idolatría del mercado y "al secucstro y a la inversión del mandamiento del amor al prójimo":35.

El mito liberal presupone que los seres humanos son demasiado egoístas para poder emprender un proyeclo común. El extremo contrario supone que la planificación económica pueda canalizar la generosidad nalural hacia una prosperidad compartida. En realidad, el ser humano persigue sus intereses personales y, al mismo tiempo, "permanece abierto a los reclamos de la solidaridad." Por eso, mantiene Assmann, para ser viable, cualquier proyecto histórico tiene que tomar en cuenta " $y$ sopesar, según las circunstancias, el potencial conjunto de esos dos elementos definitorios del ser humano (planificación con mercado/ mercado con planificación)".w.

Es necesario, por lo tanto, combinar ética y mercado. Pero para Assmann, la metafísica y la religión ya no son capaces de generar los consensos necesarios para legitimar la política social, que exige este objetivo. Por ello propone el principio de respeto a la dignidad de la "corporeidad viva", concepto que incluye a todos los cuerpos humanos, pero que se extiende a los sistemas bio-sociales de los que los seres humanos son parte ${ }^{37}$.

Enrique Dussel, argentino que vive actualmente en México, está también en la línea de la transformación social más allá del capitalismo. En su reciente libro de 600 páginas, Etica de la liberación en la edad de la globalización y de la exclusión, busca fundamentar la ética de la liberación ${ }^{\text {th }}$. Aunque se trata de una obra filosófica que no se limita a la crílica de la economía de mercado, tiene gran importancia para el tema que nos ocupa. El libro de Dussel marca un avance notable en el desarrollo de su propio pensamiento ${ }^{\text {iy }}$, ciertamente, tendrá

35. Ibid., p. 265.

36. Ibid., pp. 285-286.

37. IbId., Pp. 265, 286-287. Assmann toma prestado el concepto de "corporeidad viva" del pensador italiano Umberlo Eco. Ivone Gebara asume el mismo criterio de Eco. Cfr. I. Gebara, Longing for Running Water: Ecofeminism and Liberation, Minneapolis, 1999, p. 210.

38. E. Dussel, Ética de la liberación en la edad de la globalización y de la exclusión, Madrid, 1998.

39. Según Carlos Beorlegui, "no cabe duda de que este último trabajo representa la obra 
impacto en la ética teológica y es importante para la evaluacón ética de los sistemas económicos ${ }^{4 t}$.

Dussel construye su ética sobre un trípode de crilerios (más adelante introducirá un segundo trípode). Propone un fundamento material y otro formal para las obligaciones élicas, a lo cual añade una exigencia: que tales obligaciones sean prácticamente faclibles. El primer criterio (el material) consiste en la obligación de buscar la "producción, reproducción y desarrollo" de cada vida humana, en comunidad". Promover la vida, en su riqueza multifacética, es el criterio-deverdad de la ética. El segundo criterio (el formal) es el de validez. Los principios éticos intermedios, aquellos a través de los cuales se aplica el principio material, deben tener en cuenta el parecer de todas las personas y comunidades afectadas, como lo exige la ética del discurso de pensadores como K. O. Apel y J. Habermas ${ }^{42}$. (Digamos que al afirmar un criterio material y olro formal, Dussel rechaza todo sistema ético basado en un principio único, sean los reduccionismos materialistas, como el vitalismo de Nietzsche, sean los reducionismos formales, como la ética de Kant.) En tercer lugar, las propuestas éticas dcben ser factibles. No liene sentido exigir una economía planificada que es imposible al nivel técnico, o bien económico, político o cultural. Dussel coincide con la crílica de Hinkelammert ( $y$ de olros) al método positivista en las ciencias sociales que excluye toda racionalidad que no sea "instrumental". Pero su tercer criterio afirma la necesidad de la razón insirumental en la ética para determinar los medios aplos para los fines deseados ${ }^{41}$. Según estos tres principios generales, para que una acción sea ética debe buscar producir y desarrollar la vida humana de la manera más adecuada (en su contexto imprescindible del ambienle natural), tomando en cuenta el parecer de todas las partes afectadas ${ }^{44}$.

cumbre de E. Dussel, constituyendo un excelente trabajo de síntesis y de madurez", "La nueva ética de la liberación de E. Dussel", Realidad 72 (1999) 689.

40. Conviene señalar otra obra de ética filosólica de alta calidad: Jordi Corominas Escudé, Esica primera. Aportación de X. Zubiri al debate ético contemporáneo, Bilbao, 2000. Corominas, quien trabajó muchos años en Centroamérica, desarrolla el pensamiento del filósofo vasco Xavier Zubiri.

41. Dussel, Etica de la liberación, pp. 132, 140. Aquí Dussel hace uso de ideas de Marx (y de Hinkelammert). Mantiene que todo el proyecto de Marx es implícitamente élico, cfr. ibid., pp. 326, 382, No. 63.

42. Dussel, Etica de la liberación, p. 214. Un acto "es 'valido'... si es 'aceptado' intersubjectivamente por una comunidad de comunicación", "Principles, Mediations, and the 'Good' as Synthesis", Philosophy Today: Supplement, 1997, p. 55.

43. E. Dussel, "Epilogue", en Linda Martin Alcoff y Eduardo Menieta (eds.), Thinking from the Underside of History: Enrique Dussel's Philosophy of Liberation, New York, 2000, pp. 269-289; cita en la p. 273.

44. Cfr. James L. Marsh, "Principles in Dussel's Elhics", Thinking from the Underside, pp. 51-67; cila en la p. 57. 
Dussel, sin embargo, no considera que estos criterios generales son suficientes. En la segunda parte del libro, aplicando la metodología "liberadora", elabora un segundo trípode de principios "críticos", en paralelismo a los primeros, desde la perspectiva de las víctimas de la historia. El primer principio crítico postula el deber de reconocer la dignidad de las víctimas, cuyas vidas han sido truncadas o desiruidas"s, lo que lleva a captar que lo que es "bueno" y "válido", según los criterios éticos dominantes (la Sittlichkeit reinante), es, en realidad, malo e inválido para las víctimas. Y esto, a su vez, implica la obligación de asumir una coresponsibildad hacia las víctimas. En segundo lugar, es necesario que las víctimas, excluidas de las tomas de decisión, desenmascaren el discurso ético dominante y elaboren una ética que responda a las causas de su opresión y apunte hacia una sociedad sin víctimas ${ }^{4 h}$. Finalmente, lo que esta nueva "ética de la liberación" propone debe ser factible, tomando en cuenta que "en el mundo del capitalismo periférico, muchas normas, adecuadamente fundamentadas material y formalmente, no son 'factibles', o por el subdesarrollo tecnológico, o por incapacidad económica, [...] etc" ${ }^{\text {"at? }}$.

Dussel considera que el capitalismo viola estos tres principios crílicos. Lejos de defender la vida, excluye a la mayoría de la mesa del banquele. También la excluye de la mesa de discusión, en la cual se decide quién vive y quién muere. Finalmente, el capitalismo hace uso de la racionalidad instrumental, en favor de sus intereses mezquinos. La conclusion es un no a la reforma del sistema, y un sí a su transformación, lo cual no significa necesariamente "revolución", pues las condiciones para ello ocurren de modo infrecuente, y la ética debe ser útil, aun cuando no se den estas condiciones, como es el caso en la actualidad ${ }^{44}$.

Resumiendo lo dicho en este apartado, este grupo de teólogos recalca la promoción de la vida humana, en el contexto del ambiente natural, el reconocimiento de la dignidad de las víctimas y la obligación de tomar en cuenta su parecer, al formular normas éticas. Aceptan el mercado como necesario, pero consideran que, sin fuertes controles, la lógica del mercado atenta contra la vida de los débiles. Reconocen que el intento de incluir a todos en la economía y en la toma de decisiones será un desafío, en alguna medida, al privilegio de los poderosos. Por eso, la ética de solidaridad de Hinkelammert es una ética de resistencia. La acción solidaria implica "un conflicto continuo y constante", ya

45. Esta idea, central para Dussel desde hace mucho tiempo, proviene de E. Lévinas, Totalité et Infinit. Essai sur l'Extériorité, The Haguc, 1968.

46. Enrique Dussel, "Globalization and the Viclims of Exclusion: From a Liberation Ethics Pcrspective", The Modern Schoolman LXXV (January 1998) 119-155; cita en la p. 148.

47. Dussel, Erica de la liberación, p. 263.

48. Ibid., pp. 525-538. 
que la tensión entre el mercado y la producción de vida para todos es el "descendente legítimo de la lucha de clases"

La sospecha hacia el mercado y el tema de la conllictividad están menos presentes en otros moralistas que hablan más de reforma - si bien de reforma radical- que de transformación, y recurren más a la doctrina social católica que a la teoría social crítica.

\subsection{Reforma social: evangelio y doctrina social de la Iglesia}

Tony Mifsud de Chile y Juan Carlos Scannone de Argentina han hecho una amplia relectura de la doctrina social católica sobre la economía de mercado ${ }^{\text {st. }}$.

Mifsud concluye con varias observaciones. A pesar de los beneficios del mercado, dice, una economía de mercado termina excluyendo a los débiles de la sociedad, ya que, por sí solos, los mercados no distribuyen los bienes, según la necesidad social. Por lo tanto, una economía cuyo criterio definitivo es la ley de la oferta y la demanda debe ser rechazada, porque no "ayuda a lodos los miembros de la sociedad a realizarse como personas humanas"s!.

Según Mifsud, el éxito de un sistema económico consiste, en último término, en su capacidad para incluir a todos los miembros de la sociedad, en el proceso de producción y sus beneficios. Por tanto, cuando el bien común lo requiere, la autoridad pública tiene que intervenir en la economía, aun cuando ello genere ineficiencia. $Y$ es que la re-distribución puede ser más importante, en términos humanos, que la eficiencia. A fin de cuentas, ¿no se acepta fácilmente la intervención del Estado cuando el capital financiero está en crisis? Para Mifsud, "en términos generales, a mayor igualdad de condiciones dentro de una población menos necesaria resulta la intervención; pero a menor igualdad de condiciones, se precisa de una mayor intervención en la redistribución de los beneficios producidos en una sociedad"s2.

En gran parte, Scannone coincide con esta postura. Sostiene que Pío XI tenía razón cuando rehusó condenar la economía capitalista como tal (es decir, una economía en la que unas personas proporcionan el capilal y otras su trabajo). Pero lambién cree que el "imperialismo económico" y el “'imperialismo' inlernacional del dinero" del cual ya se lamentó Pío XI, en 1931, son realidades acluales. Mantiene que el principio de subsidiaridad del papa, quien reconoce la

49. Hinkelammert, El mapa, pp. 258, 268.

50. Tony Mifsud, “Economía de mercado. Interrogantes éticos para una acción solidaria", Medellín 22 (1996) pp. 89-168; Juan Carlos Scannone, "Economía de mercado y doctrina social de la Iglesia. Aporte teológico desde y para América Lalina", ibid., pp. 57-87.

51. Mirsud, "Economía de mercado", p. 139.

52. Ibid., p. 157. 
imporlancia de la sociedad civil, debe conducirnos hoy a la "democracia económica"s.3. Para Scannone, esto no significa una economía con una dimensión social, sino una "social-economía de mercado", en la cual la sociedad orienta al mercado, excluyendo "relaciones hegemónicas de poder social"s4.

De lodos los teólogos latinoamericanos, tal vez Scannone es quien más concreta los contornos de un orden socioeconómico más humano. En otro ensayo reciente, inspirándose en las reflexiones del elicista suizo Peter Ulrich, esboza las características de la "democracia económica". Ulrich argumenta que la teoría económica tiene que encontrar su lugar propio dentro del discurso ético de la comunidad, a la cual afectan las polílicas económicas - una postura parecida a la de Hinkelammert y Dussel. Para Scannone, la relación adecuada entre la ciencia económica y la élica es una relación "calcedoniana": ética y economía son racionalidades distintas, pero inseparabless.

También coincide con Ulrich al sostener que el capital personal (mi casa, mi tienda) y el gran capital institucional (corporaciones anónimas) no deben tratarse de la misma manera, ni jurídica ni éticamente. En particular cuando una empresa afecta a la comunidad, todos los afectados deben participar en la definición de los parámelros de sus operaciones, si bien permitiendo la administración eficiente y los beneficios razonables. Los "derechos de los [...] afectados pueden ser distintos: de consulta, de queja, de indemnización, de coparticipación en las (o en algunas) decisiones, etc." "sh.

Scannone estima que estos criteros son aplicables en América Latina. Se inclina más en favor de realidades emergentes que de ideas regulativas. Tal vez ningún teólogo lo supera en el cumplimiento del crilerio de factibilidad de Dussel. Scannone se pregunta dónde pueden haber señales de una economía alternativa, que surja de la realidad social de América Latina, y responde que aparecen en dos niveles, que considera complementarios.

Por un lado, observa esfuerzos (aunque no los especifica) por hacer que el mercado funcione dentro de un marco ético y jurídico - al estilo favorecido por muchos cristianos europeos y socialdemócratas después de la segunda guerra

53. Scannone, "Economía de mercado", p. 62. Hace referencia a la Quadragesimo anno, Nn. 101-102, 109, 179.

54. Ibid., pp. 79, 82. Cfr. Centesimus annus, No. 52.

55. J. C. Scannone, "Hacia la transformación comunicativa de la racionalidad económica", en Etica y economia. Economía de mercado, neoliberalismo y ética de la grafuidad, J. C. Scannone y Gerardo Remolina (eds), Buenos Aires,1998, Pp. 147-184. Cfr. P. Ulrich, Transformation der ökonomischen Vernunff. Fortschritsperspectiven der modernen Industriegesellschaft, Bern-Sluttgart, 3a ed., 1993.

56. Scannone, "Hacia la transformación", pp. 176-177. Nólese la afinidad con el criterio fundamental de la élica de discurso de Apel y Habermas. 
mundial. Por otro lado, observa que, en América Latina, una "economía popular de solidaridad [con] mercado democrático"s7 está creciendo, en lel sector formal y la informal. Sus participantes incluyen cooperativas, empresas autogestionadas de trabajadores, huertas comunitarias y otras formas de propiedad asociativa. Muchas de estas empresas responden al desafío de ser eficientes y competitivas, gracias a lo que el economista chileno Luis Razeto llama el "factor C" (factor comunidad) ${ }^{5 s}$. Como Razelo, Scannone cree que hay que tomar en cuenta el factor $\mathrm{C}$ como un elemento central de la realidad económica - a la par del trabajo, el capital, la tecnología, etc.- - a la hora de delerminar la viabilidad de estas empresas alternativas. Al mismo tiempo, Scannone reconoce que el éxito de las empresas de autogestión y cooperativas dependerá de la consolidación de la democracia política, social y económica.

\section{3 ¿Cuánto de mercado?}

Los dos grupos de teólogos que hemos analizado manejan discursos diferentes, pero no se deben exagerar las diferencias prácticas implicadas. Todos ellos reconocen la necesidad del mercado. Todos ellos afirman lambién la necesidad de enmarcarlo dentro de instrumentos jurídicos para asegurar la satisfacción de necesidades básicas de toda la población, superar la exclusión y permitir la participación social. Para algunos de ellos es lambién necesario que el pueblo pueda pedir cuentas de cómo se maneja la propiedad productiva que les afecta de forma directa. Otros recalcan que armonizar mercado y élica no traerá conflictos y que llevará más allá del capitalismo. Lamentablemente, a pesar de importantes esfuerzos alternativos, nadie vislumbra una sociedad alternativa en el horizonte actual. En gran parte, las razones son políticas y éticas.

\section{Política, sociedad civil, cultura}

El desafío de combinar ética y mercado hace ineludible tratar el tema del papel del gobiemo, en la economía. Promover la intervención de la autoridad pública en la economía resulta ahora problemálico, en primer lugar, por la ideología neoliberal $y$, en segundo lugar, por la falta de eficacia de las políticas keynesianas (a nivel nacional), en una economía cada vez más transnacional. Esto contribuye, por último, a una crisis de legitimidad de partidos políticos y gobiernos, crisis agravada por los medios de comunicación con mayor capacidad para sacar a la luz la corrupción y la ineptitud oficiales.

En las últimas dos décadas, en América Latina, los gobiemos y las clases políticas han ido perdiendo brillo y prestigio, mientras que se ha dado un flore-

57. Scannone, "Economía de mercado", p. 85.

58. Sobre el factor C, cfr. Gaspar F. LoBiondo, "Etica, educación popular económica y solidaridad", en Scannone y Remolina (eds.), Etica y economia, 428.432. Sé encuentra material bibliográfico en ibid., p. 168, Nn. 20 y 21. 
cimiento de la sociedad civil, es decir, de aquellos grupos que son "intermedios", no gubernamentales o empresariales. (Los paises centroamerica- nos golpeados por sus crísis político-militares, parecen haber quedado atrás en este resurgir.) Así, la sociedad civil se ha convertido en el lugar de los esfuerzos populares a favor del cambio y en objeto de reflexión. Para comprender lo que está ocurriendo, es necesario prestar atención a la evolución de las relaciones sociales, las costumbres y los valores que encarnan —es decir, la cullura.

\subsection{Polílica y gobierno}

Los moralistas exigen una mayor intervención -incluso orientación-gubernamental en la economía, pero muchos insisten también en la necesidad de rendir cuentas a la sociedad civil. Aunque es consciente de la debilidad histórica de los estados latinoamericanos, José Comblin, desde Brasil, aboga por la construcción de un Estado de bienestar social, eficiente, pero fuerte, y por una estrategia de desarrollo industrial público-privado ${ }^{54}$. Pero ambas cosas son metas a largo plazo.

Todos reconocen la impotencia de América Latina ante las condiciones impuestas por las naciones ricas del norte, sobre todo Estados Unidos. Como dice Miguel Manzanera de Bolivia, "la actual estructura política intemational, con las desigualdades extremas entre paises, contradice los principios éticos del destino universal de los bienes y de la misma democracia"wn. Emilio Albistur de Argentina recuerda que los documentos papales recientes y de Medellín notaron y evaluaron la proliferación de las relaciones asimétricas entre naciones y que ya Juan XXIII, consciente de la insuficiencia de los estados-naciones para asegurar el bien común universal, recalcó la necesidad moral de una autoridad pública universal ${ }^{\text {th }}$. Sin esa autoridad, no sólo en el campo político, sino también en el económico, se estanca la cooperación regional, y los gobiernos locales no pueden asegurar el bien común nacional.

\subsection{Sociedad civil y cultura}

La escasa posibilidad de cambios a nivel nacional e international y el crecimiento de la sociedad civil han hecho necesario y posible volverse hacia lo

59. "El mayor problema político en América Latina es la debilidad del Estado", Comblin, Called for Freedom: The Changing Context of Liberation Theology, Maryknoll, 1998, p. 123. Traducción castellana, Cristianos rumbo al siglo XXI, Madrid. Comblin acepta las propuestas que se hacen en el conocido libro de Jorge G. Castañeda, Utopía desarmada. Las intrigas. dilemas y promesa de la izquierda en América Latina, Barcelona, 1995.

60. Miguel Manzanera, "Crítica filosófica del neoliberalismo (II)", en Etica y economía, pp. 77-145; cita en la p. 123.

61. Emilio A. Albistur, "Globalizar la solidaridad. Desarío para la pastoral y la doctrina social de la Iglesia", CLAS 48 (1999) 13-33. Cfr. Pacem in terris, No.137. 
local. Puesto que en lo local hay mayores posibilidades de avances democráticos, escribe Comblin que "el objetivo político a las inmediatas es formar una sociedad civil desde las bases"

La importancia actual de la sociedad civil se debe, en parte, a las nuevas realidades económicas. Ejemplo importante es la ya mencionada emergente economía de la solidaridad. Es parte de un fenómeno más amplio, que incluye el crecimiento de grupos organizados de vecinos, mujeres, csludiantes, trabajadores, indígenas, afroamericanos, ambientalistas, defensores de derechos humanos, consumidores, grupos religiosos y todo tipo de organización no gubemamental. Scannone caracteriza este nuevo fenómeno continental como "neocomunitario"k.3. (que no se debe confundir con el "comunitarismo" de la reciente teoría social de Estados Unidos). En comunidades pobres, sobre todo, estos grupos luchan por la vida con dignidad, muchas veces en alianza con grupos foráneos, que forman parte de lo que Pedro Trigo llama la "internacional de la vida"

Se acepta que en la primera época de la teología de la liberación se descuidó la realidad cotidiana y subjetiva de los pobres, quienes, en lugar de despertar como sujeto colectivo de la transformación social, abrazaron la libertad relativa de la vida urbana, con todas sus ambigüedades ${ }^{\text {his. }}$. Hoy se afirma y se analiza más la complejidad de esta realidad y la dimensión "local" de los pobres. Entre otros factores, el énfasis de la teología feminista en lo cotidiano impulsa a prestar más atención a cómo la gente organiza su vida, sus relaciones sociales (con vecinos, de género, familiares, laborales y económicas), sus aspiraciones, costumbres y valores - en una palabra, su cultura, aquella realidad desatendida por la derecha liberal y la izquierda marxista, descuidada, de hecho, por el pensamiento político de la modernidad en general. Se reconoce mejor la necesidad de comprender cómo los pobres encuentran sentido en sus vidas y cómo elaboran una variedad de estrategias de sobrevivencia y liberación locales. Esta densa realidad constituye un desafío para la teología moral ${ }^{\text {tht }}$.

62. Comblin, Called for Freedom, p. 137.

63. J. C. Scannone, "El futuro de la reflexión teológica en América Latina. El comunitarismo como alternativa viable", Stromata 53 (1997) 13-43.

64. Ibid., p. 24.

65. Cfr. Simón Pedro Arnold, "Norle-Sur: Exclusión de los pobres", Páginas 151 junio 1998) 50-56. Asi, los pobres han dejado a los militantes y tcólogos en la "orfandad" (ibid., p. 54). Muchos también subcslimaron la ferocidad con que las autoridades iban a reprimir los esfucrzos a favor del cambio social.

66. Márcio Fabri dos Anjos, "Encruzilhadas da ética tcológica hoje", en Teologia e novos paradigmas, Sâo Paolo, 1996. Citamos la traducción castellana, "Encrucijadas de la ética teológica actual", en Teología y nuevos paradigmas, Bilbao, 1999, pp. 175-194; el texto citado está en pp. 188-191. Cfr. García Durán, "Teología moral", p. 78. Según Eduardo Sola de México, "cl peso de una ética cristiana encarnada en 
América Latina está en la encrucijada de profundos cambios culturales. Hasta hace poco, la mayoría de la población era socializada en las culturas rurales tradicionales. Ahora, la mayoría crece en los centros urbanos, en medio de un ethos liberal. Si se añade a esto la cultura de los medios de la comunicación masiva, importada de Estados Unidos, la migración masiva y las oportunidades de viajar sin precedentes, el resultado es el pluralismo, la crisis de autoridades tradicionales (de los mayores, la familia, la lglesia, la escuela, el gobierno, etc.), las brechas generacionales, las crisis de identidad y la confusión moral. En este contexto, varios autores han contrastado los valores tradicionales y la cultura liberal y han pintado las líneas maestras de la cultura posmodema, en América Latina, además de nuevas versiones de un ethos radical ${ }^{\text {h? }}$.

Decir que hay confusión moral no quiere decir que la práclica moral se deteriora masivamente. Pero si antes muchas veces se acataba y no se cumplía, ahora, sobre todo entre jóvenes urbanos, no queda claro ni qué se quiere o se debe acatar. La juventud urbana vive una cultura hibrida, dice el argentino Jorge Seibold. Según él, "el 'imaginario social urbano' de nuesıras grandes ciudades latinoamericanas contiene en mayor o menor grado al menos tres componentes fundamentales: la Iradicional, la moderna y la posmodema"ws. La familia, la comunidad y la coslumbre predominan en el ethos traditional que valora la vida, el orden y la trascendencia. La libertad individual y la eficiencia caracterizan el ethos liberal modemo. El ethos posmoderno (o post-ilustración) fragmentado tiende hacia un cinicismo moral y a la superficialidad, pero también registra una protesta sana, en nombre de la autenticidad, contra los anti-valores del tradicionalismo y la modernidad ${ }^{n !}$.

un horizonte cultural greco-romano-occidental y exportada como 'la ética cristiana', le ha impedido a la Iglesia su propio crecimiento, además de que ha cercenado a pueblos y culturas de su bagaje ético propio", Eduardo E. Sota García, "Etica cristiana y cultura", Voces 10 (1997) 89-93; la cita en p. 93. Cfr. Humberto Encamación Anizar, "Cristianismo e integración cultural en México frente a la cultura de la desigualdad", ibid., pp. 103-111.

67. Véase Jorge Seibold, "Ciudadanía, Iransformación educativa e imaginario social urbano. La problemálica actual de los valores ante el desafío de la regionalización y el impacto de la globalización", Stromata 55 (1999) 53-89, especialmente la p. 59. Este artículo liene bibliografia de los escrilos anteriores del mismo autor sobre el tema. Cfr. también Dean Brackley, "Hacia un ethos radical", Revista Latinoamericana de Teología 44 (mayo-agosto, 1998) 189-215; Gustavo Gutiértez, "Desafios de la posmodernidad", Páginas 162 (2000) 36-47; Comblin, Cristianos rumbo al siglo XXI, Capítulo 7; Nilo Agostini, Teologia moral: entre o pessoal e o social, Petrópolis, 1995, Parte I.

68. Seibold, "Ciudadania", p. 60.

69. Jorge R. Seibold, "Imaginario social, trabajo y educación. Su problemática actual en medios populares del Gran Buenos Aires", en Etica y economía, pp. 369-408. 
Scannone opina que los nuevos movimienlos de la sociedad civil representan una especie de "modernización reflexiva y post-tradicional", que augura un ethos nuevo. Aunque con frecuencia "más allá de la izquierda y de la derecha" y de estilo posmodemo, estos movimientos rescalan valores comunitarios tradicionales ante el individualismmo competitivo ${ }^{n 1}$. Sin embargo, en algunos casos, encarnan un ethos radical o liberador que es más participativo y democrático que autoritario ${ }^{7}$.

Aunque la sociedad tradicional está en crisis, es posible que el espíritu generoso y comunilario del campo no lermine en el destino del yugo de bueyes y del telar. En 1998, un grupo de filósofos jesuitas (algunos son también teológos) publicaron una colección de ensayos, Etica y economía ${ }^{72}$, que estudia la relación entre el mercado y dos valores centrales de las culturas latinoamericanas. Los autores llaman a éstos nostridad y gratuidad. Tomados a una, se relieren a un sentido elemental de solidaridad ("nosotros") y a hábitos de dar y recibir mutuos, con un mínimo de cálculo. La nosıridad y la gratuidad generan una racionalidad que está en pugna con el individualismo, la competitividad, la racionalidad instrumental y la lógica mercantil del liberalismo moderno"s. Sin embargo, el grupo cree que las dos lógicas pueden comple-mentarse y que unirlas en la práctica constituyen un desafío moral fundamental.

Según estos autores, la nostridad y la gratuidad, más que meras idiosincra- cias culturales, surgen de la misma condición humana. Por tanto, el individua- lismo competitivo está basado sobre una antropología defectuosa. Antonio Ocaña de Uruguay invita a "abrir los ojos ante la amplitud de la gratuidad". Hemos heredado toda la naturaleza ambiental y todas las obras públicas y culturales gratis. Ocaña nota cómo la gratuidad es, además, altamente eficaz y eficiente ${ }^{74}-$ como Razeto reconoce en sus estudios de aquel factor $\mathrm{C}$ que encarna la nostridad.

70. Scannone, "El futuro", p. 34. En las frases ciladas resuena el pensamienlo del sociólogo británico Anthony Giddens.

71. Brackley, "Hacia un cthos radical”, pp. 204-213.

72. Cfr. la nola 55 de csic artículo. Sc trata del quinto libro de una seric. Para los primeros cuatro, véasc Vicentc Santuc, "Presentación de los libros del Equipo jesuita latinoamericano de reflexión filosófica", Stromata 54 (1998) 303-311. Un scxio volumen, sobre política, apareció en 1999.

73. El grupo profundizó en la idea de graluidad, en el segundo volumen, Irrupción del pobre y quehacer filosófico. Hacia una nueva racionalidad, Bucnos Aires, 1993. Reflexionó sobre la nostridad, una "antropología de nosotros," especialmente como reflejado entre los guarani, en su tercer volumen, Hombre y saciedad. Reflexiones filosóficas desde América Latina, Bogotá, 1995. Cfr. B. Melià, "La comunidad de comunicación en K.-O. Apel y en la filosofía guaraní", ibid., pp. 23-26; M. Manzanera, "Metafisica de la nostridad. Hacia una filosofia de la liberación como nostrificación”, ibid., pp. 91-130.

74. Antonio Ocan̄a, "Interés: gratuidad y ley", en Etica y economia, pp. 227-313. 


\subsection{Reflexiones finales sobre la sociedad}

El nuevo énfasis en la sociedad civil parece alinado. Por otra parte, las microiniciativas populares enfrentan inmensos obstáculos, y aquel Estado de bienestar social, fuerte y eficiente, no aparece en el horizonte actual. Ante esta realidad dura, quiero temninar este apartado con dos observaciones.

Primero, desde el Perú, Francisco Chamberlain advierte sobre la tentación "moderna" de proponer soluciones simples para problemas complejos: el mercado solo (liberales), el Eslado solo (la izquierda), o la sociedad civil sola. Considera que cada uno de ellos aporta algo necesario, pero insuficiente. La tercera tentación -el "basismo", que espera cambios sólo desde abajo, desde la sociedad civil- acecha a muchas personas cristianas. Según Chamberlain, esta actitud olvida cómo Jesús trató de influenciar a los no pobres y a las autoridades de su tiempo ${ }^{75}$.

Segundo, los conservadores apelan al principio de subsidiaridad para justificar las privatizaciones y el Eslado mínimo, exagerando la subsidiaridad, a expensas del bien común. Como bien afirma Scannone, el principio de subsidiaridad debe empujarnos hacia la democracia económica. Las versiones de este principio en los documentos papales más recientes ${ }^{\text {th }}$ (no las antiguas) afirman el deber de los gobiernos de posibilitar la participación acliva de la ciudadanía como agente social "adulto", contribuyente al bien común y no mera receptora del producto social. Pero para aplicar el principio de subsidiaridad debidamente es necesario tener en cuenta, más de lo que suele hacerse, la desigualdad conflicliva, que caracleriza la vida económica, sobre lodo en América Latina. El principio de subsidiaridad exige que el gobierno defienda a los actores económicos vulnerables en mercados muy imperfectos, aun sin tener en cuenta los problemas de corrupción y la competencia desleal. Lejos de estar en conflicto con el bien común, el principio de subsidiaridad debe contribuir a realizarlo.

\section{Consolidar la renovación post-conciliar}

El enfoque actual en la densa realidad de la sociedad civil y la cultura contr1buye a un mayor interés para consolidar la renovación de la teología moral postconciliar, de talante personalista, en un continente donde la cultura autoritaria sigue pesando en la Iglesia y la sociedad. No sorprende, pues, el interés que se nota en el problema de la libertad personal dentro del contexto de las relaciones sociales locales y concretas.

75. Francisco Chamberlain, “CCómo entendemos hoy el compromiso social y político?”, Páginas 149 (febrero 1998) 13-19.

76. Por ejemplo, Centesimus annus, No. 48. 
Recientemente, el brasileño Antônio Moser ha hecho un repaso de los últimos cincuenta años de renovación post-conciliar de la moral, principalmente european. Celebra cómo esta corriente de la teología moral ha rescatado los símbolos bíblicos fundamentales de la alianza, el reino de Dios y el seguimiento de Jesús, con marcado énfasis en el amor, la misericordia y el entusiasmo de las bienaventuranzas más que en la ley, el deber y la justicia punitiva ${ }^{7 w}$. Al mismo tiempo, aunque su apreciación es en gran parte positiva, Moser observa que esta teología moral se ocupa más de las relaciones sociales "cortas", de la amistad y la intimidad sexual, que de las "relaciones largas", de la vida instilucional o las relaciones de seres humanos con el medio ambiente no-humano. Toma más en serio la psicología y la antropología cultural que las ciencias sociales o del medio ambiente. Moser también lamenta la ausencia en la moral renovada de una "perspectiva dialéctica de una sociedad conflictiva, y, sobre todo, la perspectiva de los pobres" ". Esta limitación conduce a la ausencia de un llamado a las transformaciones sociales profundas, que son tan urgentes. Finalmente, nota la poca colaboración ecuménica e inter-religiosa, en la tcología moral post-concilian".

El también brasileño Márcio Fabri dos Anjos propone una ruptura decisiva con la casuística legalista. Señala la brecha entre la moral oficial y la moral popular real. Sin caer en pragmatismos crudos, escribe Anjos, es necesario evitar la insistencia en normas abstractas "sin al menos preguntar si 'funcionan" "'l. Mientras la teología moral habla de casos límile, el realismo nos obliga a admilir que la mayoría, en América Latina y en el mundo, ha estado viviendo en situaciones límite de pobreza, por muchos años. La teología moral necesita escuchar a las víctimas en tales "situaciones excepcionalcs", como son las de los oprimidos y homosexuales. También debe escuchar a las mujeres, quienes exigen una forma de argumentación y de pensar éticos que incorporen las razones del corazón, una aproximación más holística de la persona que supere los dualismos cuerpo-alma y los modos patriarcales de desarrollar la élica. El pluralismo de hoy demanda un procedimienlo más participativo en el desarrollo de los principios éticos ${ }^{\mathrm{k} 2}$.

77. Antônio Moscr, "Moral renovada aos cinqücnta anos", Revista Eclesióstica Brasileira 60 (2000) 557-577.

78. Ibid., p. 564.

79. Ibid., p. 574.

80. Ibid., pp. 574, 576. Moser también ha cscrito un libro de gran finura sobre el pecado, tratando varios aspectos desde cl punto de vista biblico, histórico y sistemático, y con especial atención al contexto cultural, desde donde surgen los símbolos y conceptos de pecado. A. Moser, $O$ pecado: do descrédito ao aprofundamento, Pctrópolis, 1996.

81. Anjos, “Encruzilhadas", p. 185.

82. Ibíd., pp. 185-186. Véansc las obras de María Clara Luchelli Bingemer, María Pilar 
Anjos teme que la teología de la liberación haya insislido en la necesidad de un compromiso social de tal manera que pudiera haber alimentado la imagen de un dios capataz, "enfadado y exigente" "w3. José Comblin comparte su preocupación. Defiende la necesidad de una teología de la liberlad personal, que reemplace el sobreénfasis en el pecado personal y la ley. Como otros muchos, critica los recientes documentos eclesiásticos, como la encíclica Veritatis splendor (1993). La misma teología de la liberación comparte los defectos que provienen de estas deficiencias: "El mayor reproche que puede hacerse a la telogía de la liberación es que no ha dedicado suficiente atención al verdadero drama de personas humanas, su destino, su vocación y, consecuentemente, al fundamento del tema de su libertad" "Es . El reciente libro de Comblin, Vocaçāo para la liberdade (São Paulo, 1998) ${ }^{\mathrm{ws}}$ desarrolla esta teología de la libertad personal, cuyas raíces se remontan a los apóstoles Pablo y Juan. Para Comblin, la "verdadera liberación de 'uno mismo' está en el corazón de todas las luchas específicas de liberación"wh.

\section{Elicacia y credibilidad del mensaje}

Las posibilidades de cambios positivos, a corto plazo, en América Latina, son escasas. Ante tantos obstáculos, algunos teólogos se preguntan sobre la credibilidad del mensaje de la Iglesia y su eficacia. Concluimos nuestro estudio repasando sus reflexiones.

La exhorlación de Juan Pablo II, Ecclesia in America (1998), después del sínodo para las Américas exhorta a una amplia difusión de la doctrina social católica y propone que se elabore un "catecismo social". José Oscar Beozzo de Sāo Paulo ha ofrecido sugerencias para ese proyecto ${ }^{k 7}$. Beozzo recomienda que tal catecismo adopte el mélodo ya clásico de ver-juzgar-acluar, que se mostró Ian fructífero tanto en el documento Gaudium et spes del Vaticano Il como en los documentos de Medellín y Puebla, pero que se abandonó forzozamente en Santo Domingo, en 1992. También urge a que se adopten los métodos participativos, utilizados por los obispos estadounidenses, en la elaboración de

Aquino, Ivone Gebara, Elsa Tamez, Ana Maria Tepedino y Lourdes Beneria, entre otras. Me remilo al tratamiento de algunos de sus escritos, en Brackley y Schubeck, "Moral Theology in Latin America" (nola 14 del presente articulo), especialmente pp. 150-153.

83. Ibid., p. 193.

84. José Comblin, Called for Freedom, p. 197. Otro ejemplo, como lo nota Carlos Novoa, es que la leología de la liberación ha dedicado poca atención al tema de la conciencia moral, Novoa, Seguimienıo histórico, pp. 197-199.

85. José Comblin, Vocación a la libertad, Madrid, 1999.

86. Comblin, Called for Freedom, p. 201.

87. José Oscar Beozzo, "Algumas sugestôes par uma doutrina social da Igreja no continente americano", Revisła Eclesiástica Brasileira 60 (2000) 605-618. 
sus cartas pastorales de los años 1980 sobre la paz, la economía y la mujer. Los obispos estadounidenses consultaron ampliamente y pidieron testimonios, en sesiones abiertas, a los medios de comunicación.

Beozzo sugiere que el catecismo social trate los problemas sociales más graves, que Ecclesia in America ha señalado (ya mencionamos la mayoría, a lo largo del presente artículo). Para responder a la crisis medioambiental, recomienda que los cristianos aprendan de las comunidades indígenas. Beozzo propone una colaboración entre las iglesias del sur y del norte de las Américas para responder a los problemas de carácter internacional, como la especulación financiera y la deuda extema, la migración y el narcolráfico.

Ricardo Antoncich del Perú ha llamado la atención recientemente sobre los nuevos desafíos que se presentan a la doctrina social católica, tales como el significado de los derechos laborales en la producción robolizada, los derechos de propiedad de los medios de comunicación, cada vez más monopolizados. ¿Y que criterios deberán usarse para evaluar la especulación financiera, cuando los especuladores pueden "desfinanciar" a naciones enteras de un día a otro? ${ }^{88}$.

Antoncich se preocupa por la eficacia de la enseñanza social de la Iglesia. Celebra el compromiso personal de Juan Pablo Il con el problema de la deuda externa. Argumenta también que la lglesia tiene que ir más allá del discurso leynaturalista, cuando se dirige a un público más amplio que el calólico. Recomienda que se siga a la filósofa española Adela Cortina, quien combina una "ética mínima", en la línea de la ética de discurso (de Apel y Habermas), con una "ética máxima", basada en compromisos religiosos o de otros valores. Una élica mínima puede apelar a normas universales, en base a la razón. Debe caminar mano-a-mano con una ética "máxima" explícitamente cristiana, y eudaimonista, en contenido. No se puede imponer esta ética a todos. Hoy por hoy, ganará adherentes sobre todo por el "testimonio de una vida feliz"

Antoncich lamenta que la lglesia institucional no ha ya reconocido a tantos testigos heroicos suyos, algunos comprometidos hasta el martirio con los valores que la propia enseñanza social de la Iglesia promueve. Se trala de un tema trabajado por Jon Sobrino, para quien los abundantes mártires de los últimos años son "buena noticia", porque revelan un amor creible. $Y$ eso es lo que produce esperanza y vida. En adelante, "sólo una Iglesia que recoja la herencia de los mártires tendrá credibilidad entre los pobres y entre los solidarios con ellos," y "sólo una Iglesia martirial" podrá hablar de Dios con credibilidad"šn.

88. Ricardo Antoncich. "La doctrina social de la Iglesia ante desafíos del tercer milenio", Paginas 166 (2000) 6-20.

89. Ibid., p. 16; énfasis en original.

90. Jon Sobrino, “Los mártires latinoamericanos. Interpelación y gracia para la Iglesia", Revista Latinoamericana de Teologia 48 (septiembre-diciembre 1999) 329; cfr. 
Antonio González, en Guatemala, propone una solución más global al problema de la credibilidad y la eficacia, en la lucha por la justicia. González mantiene que la teología de la liberación, como todo pensamiento moderno, ha subestimado la profundidad del pecado y ha exagerado la capacidad humana para el bien. Argumenta que la justicia real no es una obra humana y que no se la puede realizar por medio de una toma de poder estatal y la implementación de un programa político, por ilustrado que sea. Al contrario, la justicia es una obra divina, que se realiza ahí donde Dios convoca a personas que, siguiendo la enseñanza y el ejemplo de Jesús, viven como iguales y comparten sus vidas y

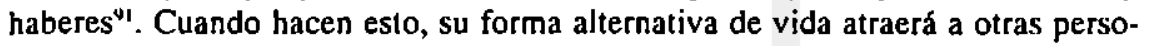
nas a unirse a su experimento. Este es el único camino para la justicia.

Ya que la justicia es obra de Dios, dice González, lo que les corresponde a los seres humanos es la fe, como lo reconoció Pablo. Cuando las personas aceptan la oferta de Dios en la Te, el Espírilu las hace capaces de vivir en fralemidad, cumpliendo su papel como sal de la tierra y luz del mundo. Las comunidades de iguales atraerán a otras personas a unirse a ellas. Es así como se vence la injusticia.

González apoya sus tesis en los estudios biblicos de los alemanes Norbert y Gerhard Lohfink y el norteamericano John Howard Yoder. Su planteamiento rescata la herencia no sólo de la Iglesia paulina primitiva, sino también la del ala radical de la reforma (menonitas, moravos, cuáqueros), que es, por su parte, heredera de los movimientos "espirituales" de la edad media. Esta tradición continúa en los evangélicos "radicales" de hoy.

El aporte positivo me parece muy importante, con tal de que no caiga en un seclarismo irresponsable. González reconoce el papel de un José, un Daniel y una Ester, en el "palacio real" para hoy. Su rol siempre será difícil, y secundario, dice. Pero afirma que el anuncio y la denuncia proféticos tienen menos importancia que la renuncia evangélica de las posesiones ${ }^{42}$.

Aquí surge la pregunta, ¿cómo deben responder los discípulos de Jesús a las multitudinarias víctimas de hoy, que no pertenecen en su mayoría a los "nuestros" (cfr. Lucas 10, 25-37)? Si bien la política no nos salva, ante los despojos organizados y la violencia institucional actuales parecen indispensables la praxis

idem., La fe en Jesucristo. Ensayo desde las víctimas, San Salvador, 1999, pp. 397. 399; idem, Terremoto, terrorismo, barbarie y utopia. El Salvador, Nueva York, Afganistón, Madrid, 2002, pp. 227-230.

91. Antonio González, Teología de la praxis evangélica. Ensayo de una teologia fundamental, Santander, 1999, especialmente los capínlos 3-6. Cfr. idem., "El evangelio de la fe y de la justicia", Revisra Larinoamericano de Teología 50 (2000) 167-190.

92. González, "El evangelio", pp. 187-188. 
de resistencia y la denuncia profética, incluso desde fuera del palacio y en contra de él.

\section{Conclusión}

La teología moral de la liberación florece en América Latina, aunque no se insista en la etiqueta "liberadora". Es, en lodas partes, una moral de la solidaridad. Esta categoría ofrece la posibilidad de enfocar adecuadamente los demás temas de la moral, con tal de que no se pierda de vista la injusticia estructural y la necesidad de superarla. Los temas centrales de la leología de la liberación siguen dando Iruto en la moral. Lo mismo puede decirse de su mélodo -el de partir de la realidad de las víclimas y de usar las ciencias sociales.

Se puede notar su eficacia también en áreas que no hemos podido tratar aqui, por ejemplo, en la bioética de Márcio Fabri dos Anjos y Jorge Domínguez, en el tratamiento de los derechos humanos por Tony Mifsud y Nilo Agostini, en la teología ecológica de José Roque Junges, Leonardo Boff e Ivone Gebara, en la teología feminista de ésta última y de Elsa Tamez, María Pilar Aquino, María Clara Luchelti Bingemer, Ana María Tepedino y Lourdes Benería y en la reflexión sobre el sida de José Antônio Trasferetti. Estos son algunos ejemplos entre muchos.

La reflexión moral sobre el problema mayor de la pobreza y el sistema económico ha avanzado y profundizado, en los últimos años. A pesar de las diferencias que señalamos, hay convergencias fundamentales: se afirma el valor central de la vida (y de la dignidad humana) y la necesidad de la participación en la toma de decisiones; se acepta el mercado, pero se insiste en controles democráticos sustantivos para superar la mortífera exclusión y defender el medio ambiente. Si bien los obstáculos políticos son formidables, la efervescencia de la sociedad civil y la realidad cultural son lugares prometedores para el cambio social y para desarrollar la teología moral. Este hecho resalta la necesidad de profundizar en el tema de la libertad y la liberación personales, consolidando la renovación personalista de la moral post-conciliar.

En el pasado, la teología moral en América Latina reflejaba, en gran parte, la moral europea, y las novedades de la moral del continente tenían un carácter fragmentario y poco sistemático. Ahora, la situación es distinta. La teología moral, en América Latina, ha llegado a su mayoría de edad. 